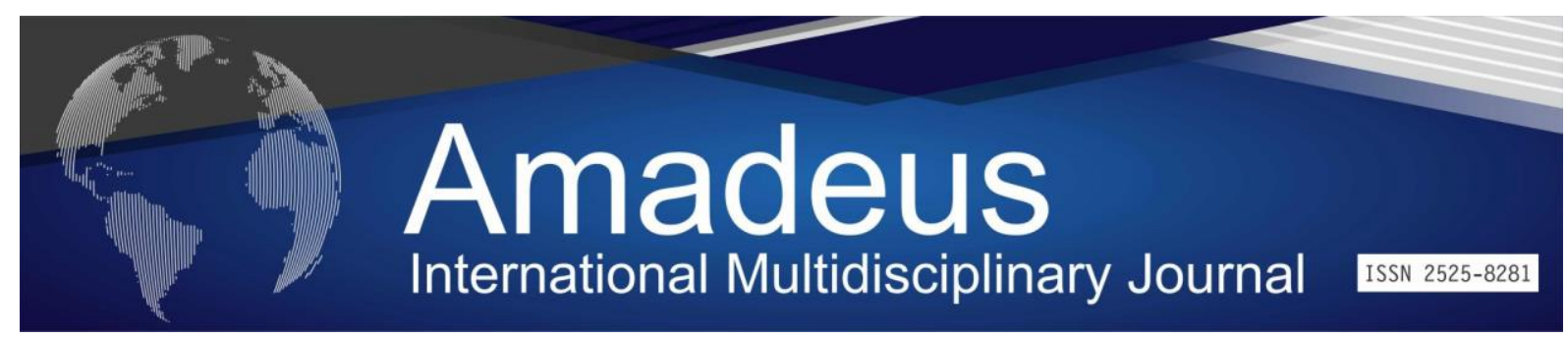

DOI: 10.14295/aimj.v5i9.136

\title{
Sleep and Immunity
}

Francinete Alves de Oliveira Giffoni $^{1}$

\begin{abstract}
Sleep has been reported in several studies as an important function of the organism, as well as its deprivation as harmful to the production of defense cells, which affects our immunity. It is also demonstrated in the literature that sleep is fundamental for the metabolism of free radicals and for the body to be able to restore cardiorespiratory functions. The weakened immune system implies an increase in the chances of contracting infectious diseases, in addition to having difficulty recovering from relatively simple illnesses such as colds and flu. This study discusses sleep and its implications for organismic immunity. The results highlighted the need to perform sleep hygiene, defined as the change from dysfunctional patterns to a new organization of habits and activities that allow better sleep induction and quality.
\end{abstract}

Keywords: Sleep; Immunity; Quality of life.

\section{Sono e Imunidade}

Resumo: O sono tem sido reportado em diversos estudos como uma função importante do organismo, bem como a privação deste como prejudicial a produção das células de defesa, o que afeta a nossa imunidade. Também é demonstrado na literatura que dormir é fundamental para a metabolização de radicais livres e, para que o organismo possa recompor as funções cardiorrespiratórias. O sistema imunológico enfraquecido implica em um aumento das chances de contrair doenças infecciosas, além de se ter dificuldade em se recuperar de doenças relativamente simples como gripes e resfriados. Este estudo discute sobre o Sono e as suas implicações na imunidade organísmica. Os resultados realçaram a necessidade de se realizar uma higiene do sono, definida como a mudança de padrões disfuncionais para uma nova organização de hábitos e atividades que permitam uma melhor indução e qualidade do sono.

Palavras-chave: Sono; Imunidade; Qualidade de vida.

\footnotetext{
${ }^{1}$ Graduated in Medicine - Federal University of Ceará (UFC). Master in Educational Evaluation / UFC and PhD in Education / UFC. Master in PNL, International Master in Systemic Integral Coaching with expertise in performance of personal and professional excellence. franvida2015@gmail.com.
} 


\section{Sono e ciclo circadiano}

O sono tem sido cada vez mais reconhecido como uma função psicobiológica essencial para o crescimento, a sobrevivência e evolução do homem. Na mitologia Grega, Hypnos é um dos deuses que interferem no espírito, levando o sono aos homens e aos deuses. Filho da deusa Nyx, a noite, tinha incontáveis filhos, chamados sonhos (Lopes, 2006). A palavra hipnose, veio pela inspiração do médico inglês, James Braid, quando conduzia os pacientes a um estado semelhante ao sono. Em latim, equivale ao somnus, estado de consciência quando a mente repousa, suspendendo temporariamente a atividade sensorial e motora voluntária, características do estado de vigília, que significa estar desperto.

Pesquisas epidemiológicas recentes indicam que, no âmbito mundial, a prevalência dos distúrbios do sono atinge até $27 \%$ da população adulta. No Brasil, aproximadamente vinte milhões de pessoas são acometidas por algum tipo de transtorno relacionado ao sono (Martinez, 1999) sendo maior a frequência entre mulheres e idosos. A insônia, definida como "dificuldade para iniciar o sono ou se manter dormindo", "sono não reparador"e "despertares noturnos" está entre as queixas mais relatadas.

Transtornos do sono podem estar associados a quadros psiquiátricos como ansiedade e depressão, a dores crônicas, fibromialgia, câncer, HIV, doenças cardíacas, uso de substâncias, insatisfação com a vida social, estilo de vida estressante (Helfenstein Junior; Goldenfum \& Siena, 2012).

Vicent e Walker (2000) verificaram que, no contexto da sociedade atual cada vez mais se associam os distúrbios do sono à preocupação excessiva com padrões e expectativas, que além de ocasionar a insônia, reduzem o tempo do sono noturno.

A alternância entre os estados de sono e vigília, mantém o organismo humano em equilíbrio conforme o ritmo natural do dia e da noite. Conhecido como relógio biológico ou ciclo circadiano (do latim circa, "cerca de", e diem, "dia") esse mecanismo controla nas 24 horas os horários adequados para alimentar-se, dormir, acordar, exercitar-se, de acordo com fatores genéticos, hormonais e ambientais (Magalhães \& Mataruna apud Jansen, et al., 2007).

Manter o organismo seguindo o ritmo fisiológico ciclo sono-vigília é fundamental para termorregulação, conservação e restauração da energia, equilíbrio entre o metabolismo cerebral e corporal garantindo a manutenção da vida. 


\section{Fatores genéticos e relógio biológico}

Michael W. Young, Jeffrey C. Hall e Michael Rosbash, receberam o prêmio Nobel de Medicina em 2017 (G1, 2017), por descobrirem um gene que regula o ritmo diário do organismo, sendo esse gene codificador de uma proteína que é sintetizada durante a noite e degradada ao longo do dia. Estudaram a relação entre o sistema de autorregulação e as proteínas que governam o ritmo circadiano, demonstrando o papel dos relógios biológicos na regulação do sono. Em um estudo pioneiro realizado em clínicas de sono encontraram e evidências de mutação gênica em 10\% das pessoas diagnosticadas com a "síndrome do atraso das fases do sono" - SAFS. Seguindo-se novos estudos, já foram identificadas pelo menos 11 proteínas relacionadas aos ritmos biológicos dos mamíferos ( Dardente \& Cermakian, 2007). E, cada vez mais verifica-se que os fenômenos relacionados à arquitetura do sono e ao ritmo sono-vigilia, tem importante papel para o equilíbrio neuroendócrino e imunológico.

\section{Evidências científicas da relação entre padrões de sono e sistema neuroendócrino}

Alterações do ciclo circadiano como a privação do sono relacionam-se a mudanças no padrão de funcionamento do Sistema Nervoso Central e disfunções no equilíbrio psiconeuroendocrinoimunológico. Atualmente, os efeitos deletérios dos transtornos do sono tem sido investigados por diversos métodos como neuroimagem (RM-Ressonancia Magnética e Petscan), EEG-eletroencefalograma e testes neuroendócrinos (Santos \& Moura, 2019).

No EEG, a atividade elétrica cerebral é registrada sob forma de ondas cerebrais (beta, alfa, delta theta, gama) cujos padrões de frequência e amplitude caracterizam cada estágio do sono. Estes estágios são divididos em dois tipos principais, tendo cada um deles funções específicas: Sono REM- Rapid Eyes Movement (padrão relacionado aos sonhos, atividade rápida, semelhante ao estado de alerta)e, sono NREM, que exerce importante papel restaurador do organismo. Nessa fase observa-se a diminuição da temperatura corporal, da frequência cardíaca e do consumo de oxigênio pelo cérebro. A redução das demandas do metabolismo possibilita a ativação dos mecanismos restauradores compensatórios, fundamentais para a saúde e imunidade (Santos \& Moura, 2019).

No sono REM, há o máximo relaxamento muscular e intensa atividade cerebral relacionada a memória e aprendizado. Realiza-se o reparo cerebral, através de processos 
capazes de promover a recuperação psicológica, organização de vivências e integração de conteúdos assimilados. Esta é uma fase fundamental para a regulação do humor e criatividade. Durante um período médio de 8 horas de sono, os ciclos se alternam, sendo cerca de $75 \%$ padrão de sono NREM (Santos \& Moura, 2019).

Figura 1 - Representação de um Hipnograma

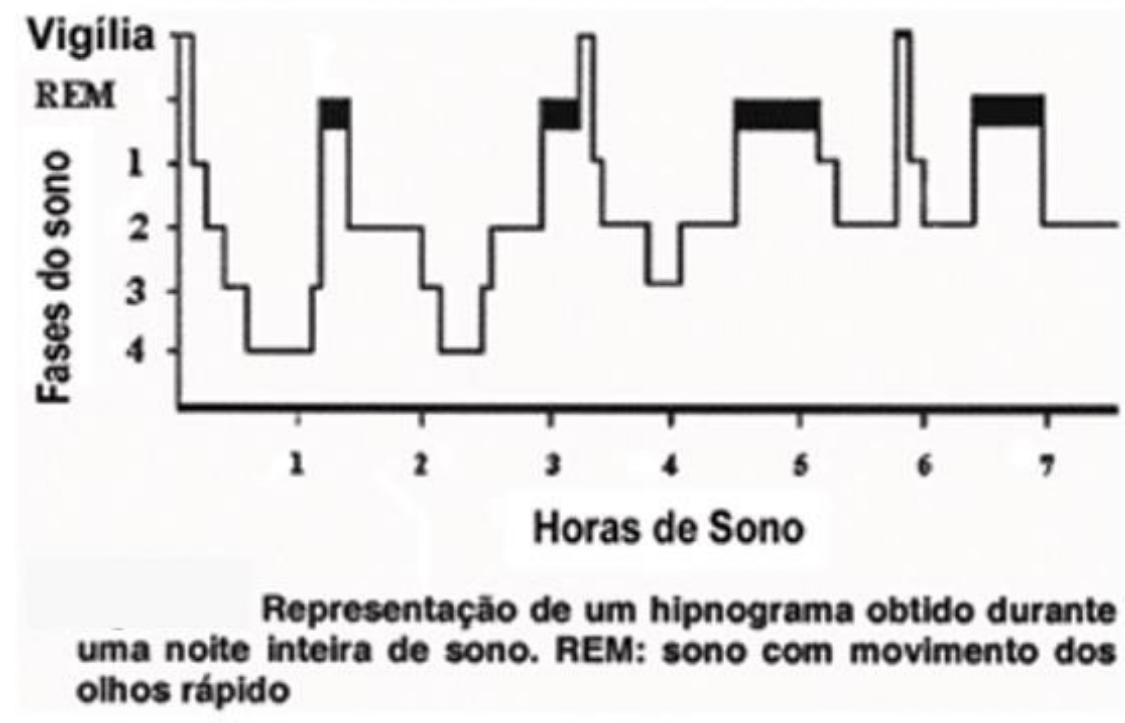

Fonte: http://o.elobot.es/tema/trastornos-del-sueno/insomnio-en-detalle

Os avanços da neuroimagem permitem identificar diferentes padrões na anatomia funcional do cérebro, associados ao sono REM e NREM. Durante o sono NREM ocorre redução da atividade em áreas do tronco cerebral, os núcleos do tálamo, hipotálamo, córtex pré-frontal, e regiões do lobo temporal. Na fase REM, há um aumento no funcionamento dos núcleos talâmicos, córtex occipital, pré-frontal e algumas regiões do sistema límbico: amígdala, hipocampo e o córtex cingulado anterior. Estão menos ativos: o córtex pré-frontal dorso lateral, giro do cíngulo e córtex parietal (Walker, 2009).

Aschoff (1979) afirma que ao escurecer, as células da retina enviam sinais que ativam o núcleo supraquiasmático, fazendo com que o gânglio cervical superior libere noradrenalina que, por sua vez, induz a glândula pineal a produzir e secretar melatonina, hormônio que vai estimular estimular o estado do sono. A liberação de melatonina é inibida pela exposição da retina à luz (Foster, 2004). E assim se estabelece o ritmo circadiano, que deve a todo custo ser preservado uma vez que envolve a orquestração de um conjunto de processos de produção e liberação de hormônios e neurotransmissores que precisam ser minuciosamente compreendidos, dada a importância de sua participação em cada fase do sono e, 
complementarmente no estado de vigília para a manutenção da equilíbrio biopsiquico do ser humano. Fatores que levem à dessincronização do relógio biológico podem desencadear desordens no organismo, além de comprometer e sua adaptação às mudanças ambientais e resposta aos fatores de estresse.

O papel do sistema neuroendócrino assume cada vez maior destaque em pesquisas envolvendo sono e imunidade. A regulação do ritmo sono-vigília está imbrincada com uma gama de neurotransmissores que interagem num processo complementar e harmônico. Durante o estado de vigília, os níveis cerebrais de acetilcolina, norepinefrina, serotonina, dopamina, histamina e glutamato estão em seus níveis mais elevados. De forma semelhante, durante o sono REM, quando acontecem processos de ativação cerebral e movimento rápido dos olhos, a acetilcolina chega a $65 \%$ dos seus níveis mais altos de vigília, e o Glutamato corresponde ao seu nível mais alto que ocorre durante a vigília, enquanto há um declínio da noeprinefrina, serotonina e dopamina.Durante os períodos de ondas lentas, sono NREM, os níveis de Glutamato e Acetilcolina caem e permanecem em seu nível mais baixo até o final. (Datta, 2010).

Como se pode ver, cada fase do sono depende de um equilíbrio entre os diversos neurotrasmissores, numa sequência harmoniosa, com produção de uns e inibição de outros a cada fase. Tudo se nicia na transição entre o estado de vigília e o sono, com a secreção da melatonina que reduz o tônus muscular. A atividade cardíaca é reduzida, os músculos relaxam e a temperatura do corpo cai. A partir desse estado, ocorrem os picos de liberação de GH - hormônio do crescimento - e leptina - hormônio que desempenha importante papel na regulação da ingestão alimentar e no gasto energético, gerando um aumento na queima de energia e diminuindo a ingestão alimentar. O Cortisol, hormônio da Suprarrenal começa a ser liberado até atingir seu pico no início da manhã, sinalizando para o despertar, no momento em que o corpo já está preparado para as atividades do dia. Vale salientar que O GH é um hormônio responsável, não apenas pela estatura das pessoas, mas também para promover o crescimento e multiplicação celular. Ele contribui diretamente com a imunidade, estimulando linfócitos B e a proliferação de células T. Acelera a formação de imunoglobulinas, além de modular a resposta de citocinas (Póvoa; Assumpção \& Araújo Apud Jansen, 2007).

\section{Privação do sono e alterações na Imunidade}

Diversos estudos têm demonstrado os prejuízos para a imunidade, causados pela privação do sono e desregulação neuro-humoral relacionada à desestabilização do ciclo 
circadiano. Um estudo com 153 homens e mulheres saudáveis, realizado na Universidade Carnegie Mellon, demonstrou que os sujeitos que dormiam menos do que 7 horas por noite apresentavam uma probabilidade três vezes maior de desenvolver sintomas de resfriado quando expostos a vírus causadores de doença respiratória (Sociedade Médica de Muriaé, 2009). A Universidade de São Paulo -UNIFESP publicou em 2003, na revista Psichosomatic Medicine resultados de uma pesquisa que apontou a privação de sono como fator de redução de $50 \%$ na produção de anticorpos em pessoas que tomaram a vacina contra a hepatite $\mathrm{A}$. Outro estudo na mesma universidade revelou que transtornos do sono estão relacionados à liberação de citocinas pró-inflamatórias no pulmão e também à recorrência de diferentes tipos de câncer como os de mama, pulmão e próstata, além de doenças cardiovasculares (Palma; Tiba; Machado; Tufik; Suchecki, 2007).

A não observância do ritmo circadiano, pode ser considerada um fator estressor, bastante significativo. Altos níveis de estresse, ou padrões de estresses sucessivos causados por longos períodos de insônia, despertares noturnos e problemas como apnéia do sono, levam à ativação do eixo hipotálamo-hipófise-supra-renal (HHSR) que integra e regula funções endócrinas e neurológicas. A desregulação desse sistema pode acarretar resultar inúmeras outras desordens e perturbações relacionadas à secreção exagerada de Glicorticoides. Há evidências sugerindo uma associação entre concentrações elevadas de cortisol e déficits cognitivos, como diminuição da memória verbal. Estudos em ratos indicam efeitos prejudiciais da corticosterona sobre a plasticidade neuronal no hipocampo diminuindo a conectividade cerebral. Nos seres humanos, observa-se desde pequenos distúrbios como cansaço e indisposição, alterações do apetite, do humor, até ações mais diretas sobre o sistema cardiovascular com aumento da pressão arterial, aceleração dos batimentos cardíacos, aumentando riscos de infarto e AVC, além de afetar diversos outros órgãos e sistemas (Alheira \& Brasil, 2005).

\section{Considerações finais}

Diante da realidade atual, o ser humano vive num contexto de impactos sucessivos, em processos constantes de mudanças sociais, econômicas e tecnológicas. A competitividade, o desgaste permanente, as exigências crescentes de responsabilidade e tomadas de decisão, não permitem o descanso necessário ao corpo e à mente. Como pode, então, com tantas demandas ao mesmo tempo, realizar sua higiene do sono, definida como a mudança de padrões 
disfuncionais para a organização de hábitos e atividades que visam a melhor indução e qualidade do sono?

A manutenção da arquitetura do sono fisiológico, suficiente na quantidade de tempo e vivenciado plenamente em todas as suas fases, é hoje uma medida emergencial, uma atitude ecológica, protetora da vida e fator indispensável à saúde e longevidade.

\section{Referências}

Alheira, Flávio Valdozende \& Brasil, Marco Antônio Alves (2005). O papel dos glicocorticóides naexpressão dos sintomas de humor -uma revisão. Rev Psiquiatr RS maio/ago;27(2):177-186

Aschoff, J. (1979). Circadian rhythms: general features and endocrinological aspects. In D. T. Kriegger (Org.), Endocrine rhythms (pp. 1-29). Nova York: Raven Press.

Dardente, Hugues; Cermakian, Nicolas (2007). Molecular circadian rhythms in central and peripheral clocks in mammals. Chronobiology International 24: 195-213. Disponível em <https://pubmed.ncbi.nlm.nih.gov/17453843/>. Acesso em 20/06/2020.

Datta, Subimal (2010). Celular and chemical neuroscience of mammalian sleep. Boston. Sleep Med,[S.1.], v. 11(5), 431-440.

Foster, R. G. (2004). Are we trying to banish biological time? www.dana.org. Cerebrum, 6(2), 7-26. Disponível em: \&lt;https://www.dana.org/article/are-we-trying-to-banishbiological-time\&gt;. Acesso em 20/06/2020

G1 (2017). Disponível em : https://agenciabrasil.ebc.com.br/internacional/noticia/201710/tres-americanos-ganham-nobel-de-medicina-por-estudos-sobre-ritmo. Acesso em 14.07.2020.

Helfenstein Junior, Milton; Goldenfum, Marco Aurélio; Siena, César Augusto Fávaro (2012). Fibromialgia: aspectos clínicos e ocupacionais. Rev. Assoc. Med. Bras., São Paulo, v. 58, n. 3, p. 358-365, June .

Lopes, W. S. (2006). Sono, um fenômeno fisiológico. Disponível em: https://biblioteca.univap.br/dados/INIC/cd/inic/IC4\%20anais/IC4-15OK.pdf\&gt;. Acesso em 20/06/2020.

Magalhães, F., and Mataruna, J. Sono. In:Jansen, JM., et al. (2007). Medicina da noite: da cronobiologia à prática clínica [online]. Rio de Janeiro: Editora FIOCRUZ, 2007, pp. 103120.ISBN 978-85-7541-336-4. Available from SciELO Books <http://books.scielo.org>.

Martinez, D. (1999). Prática da medicina do sono. São Paulo: BYK

Palma, Beatriz Duarte; Tiba, Paula Ayako; Machado, Ricardo Borges; Tufik, Sergio; Suchecki, Deborah (2007). Repercussões imunológicas dos distúrbios do sono: oeixo hipotálamo-pituitária-adrenal como fator modulador. Rev Bras Psiquiatr. 29(Supl I):S33-8. 
Póvoa, Lc.; Assumpção, Rp. \& Araújo, Cf. Endocrinologia da Noite. In: Jansen, JM., et al. (2007). Medicina da noite: da cronobiologia à prática clínica [online]. Rio de Janeiro: Editora FIOCRUZ, pp. 137-161. ISBN 978-85-7541-336-4. Available from SciELO Books http://books.scielo.org.

Revista da Universidade Vale do Rio Verde (2019). ISSN: 1517-0276 / EISSN: 2236-5362.v. 17 | n. 1 |Ano 2019

Santos, A.A.; Moura, M.D.G. (2019). Relógio Biológico: Revisão de Literatura. Três Corações. v. 17, n. 1 (DOI: http://dx.doi.org/10.5892/ruvrd.v17i1.5632).

Sociedade Médica de Muriaé (2009). Dormir menos de $7 \mathrm{~h}$ aumenta risco de doenças respiratórias. Disponível em: http://www.smm.med.br/informativo/index.php?id=203. Acesso em: 18.07.2020.

Vincent, N. K., \& Walker, J. R. (2000). Perfectionism andchronic insomnia. Journal of Psychosomatic Research, 49(5), 349-354.

Walker, M. P. (2009). The role of sleep in cognition and emotion. Ann. N. Y. Acad. Sci., [.S.1], v.1156, 168-197.

\section{How to cite this article (APA format):}

Giffoni, Francinete Alves de Oliveira (2020). Sleep and Immunity. Am. In. Mult. J., Jul to Oct. (9) 5, 144151.

Received: 08/01/2020;

Accepted: 08/17/2020. 